\title{
Outcome of Surgical Treatment of Spondylolisthesis by Decompression, Stabilization with Transpedicular Screws and Rods and Posterior Lumbar Interbodyfusion
}

\author{
Saha $\mathrm{AC}^{\mathrm{a}}$, Masud $\mathrm{MH}^{\mathrm{b}}$
}

\begin{abstract}
Background: Spondylolisthesis means forward shift of upper vertebral column over the lower vertebra. Most of the spondylolisthesis patients can be successfully treated by conservative treatment. A small but significant number of cases need surgical intervention. Design and capability of spinal instruments have drastically changed the principle of correction of spondylolisthesis by surgical interventions for better functional outcome. The objectives of this study were to assess surgical outcome, complications and return to normal activity of spondylolisthesis patients by posterior approach.

Methods: This was a prospective interventional study, carried out at NITOR and different private hospitals in Dhaka from October 2012 to December 2014. Total number of patients was 12, who underwent posterior decompression and stabilization with transpedicular screws and rods and posterior lumbar interbody fusion (PLIF).Patients were followed up for a period of six months to one year. Functional outcome was evaluated by using Modified Oswestry Low Back Pain Disability Questionnaire.

Results : Among 12 patients 5 were males and 7 were females, age ranged from 21-70 years with a mean age $43 \pm 7$ years. Three patients (25\%) had grade I, 8 patients (66.67\%) had grade II and 1 patient (8.33\%) had grade III spondylolisthesis. Follow up period was 6 months to 1 year. According to Modified Oswestry Low Back Pain Disability Questionnaire,it was observed that out of 12 patients 3 patients (25\%) had excellent, 8 patients (66.67\%) had better and 1 patient (8.33\%) had worse functional outcome.In this study overall a satisfactory (excellent and better) result was found in 11 (91.68\%) patients and unsatisfactory (unchanged and worse) result in 1 (8.33\%) patient. Dural tear occurred in 1 patient (8.33\%). Dural tear was repaired with 5/ 0 vicryl and there was no cerebro spinal fluid leakage. One patient (8.33\%) developed foot drop that was treated surgically later on.

Conclusion: Based on the results shown above, it is concluded that surgical treatment of spondylolisthesis by decompression, stabilization with transpedicular screws and rods and PLIF is a safe, effective and acceptable modality of treatment.
\end{abstract}

Key words: Outcome, posterior lumbar interbody fusion (PLIF), Spondylolisthesis.

(BIRDEM Med J 2018; 8(1): 21-25)

\section{Introduction}

Spondylolisthesis means forward shift of upper vertebral column over the lower vertebra. In 1854, Killian described the term spondylolisthesis from Greek word "spondylo" meaning spine and "listhesis" meaning to slide down a slippery path.The shift is nearly always

Author Information

a. Dr. Apel Chandra Saha, Junior Consultant, Upazilla Health Complex, Debidwar, Comilla.

b. Dr. Md. Hasan Masud, Professor of Orthopaedics, NITOR, Dhaka.

Address of Correspondence: Dr. Apel Chandra Saha, Junior Consultant, Upazilla Health Complex, Debidwar, Comilla, Bangladesh. Email: dr.apel@yahoo.com

Received: March 26, 2017

Accepted: October 31, 2017 between 4th lumbar (L4) and 5th lumbar vertebra (L5) or between 5th lumbar (L5) and 1st sacral vertebra(S1). ${ }^{1}$ Normal laminae and facets constitute a locking mechanism which prevents each vertebra from moving forward on the one below. Forward shift occurs only when the mechanism has failed.

Degenerative spondylolisthesis occurs in patients older than 40 years and rarely is identified before that time. Women are affected by this condition four to six times more often than men, probably because of ligamentous laxity and abnormal facet morphology. ${ }^{2}$ Risk factors include gymnastics, weight lifting, dancing, playing 
football and volley ball. Children suffer this condition as a result of birth defect or injury. Conservative treatment is suitable for most of the patients. Conservative treatment method includes wearing back brace, non steroidal anti-inflammatory drugs (NSAID), physiotheraphy and epidural steroid injection. A small but significant number of patients need surgical intervention.Surgical treatment is indicated if there is persistence or recurrence of symptons for at least one year with conservative treatment and if the symptom are persistent and progressive or if the condition is disabling and interferes with work and there is significant neurological deficit. ${ }^{3}$ There is no uniform agreement among surgeons about the optimal treatment. But surgery provides better clinical outcome for spondylolisthesis and fusion provides better outcome than decompression alone. Surgical procedures are as follows: 1. Posterior decompression, pedicle screws and rods fixation and posterolateral fusion 2. Posterior decompression, pedicle screws and rods fixation and posterior lumbar interbody fusion (PLIF). 3.Posterior decompression, pedicle screws and rods fixation and transforaminal lumbar interbody fusion (TLIF). In our approach, we followed the second one. The objectives of this study were to evaluate the effectiveness of the surgical technique among selected Bangladeshi spondylolisthesis patients.

\section{Methods}

This was a prospective interventional study, carried out at National Institute of Traumatology and Orthopaedic Rehabilitation (NITOR) and different private hospitals in Dhaka from October 2012 to December 2014. Total number of patients was 12 , who underwent posterior decompression and stabilization with transpedicular screws and rods and PLIF. Among them 5 (41.67\%) were males and 7 (58.33\%) were females, age ranged from 21-70 years, with a follow up period of 6 months to 1 year. Patients were selected on the basis of history, physical examination, radiological and MRI findings. Patients were included above the age of 20 years who failed to conservative treatment. Patients who had pathological fracture, fracture dislocation with complete paralysis were excluded from this study. Functional outcome was evaluated by using Modified Oswestry Low Back Pain Disability Questionnaire.

\section{Follow up}

The detail follow up schedule evaluation was selected to be conducted monthly for 3 months, then at 6 months, 9 months and 12 months after surgery. The evaluation included clinical and radiological assessment. The clinical evaluation included pain, functional status, and range of movement of spine, muscle power, instability and straight leg raising (SLR). Radiological evaluation included sign of union.

\section{Results}

The result was evaluated by using Modified Oswestry Low Back Pain Disability Questionnaire. Regarding age distribution, maximum patients were within 51-60 years $(5,41.67 \%)$ with a mean age 437 years. Five patients were males (41.67\%) and 7 were females (58.33\%). Most of the patients were housewives( 7, 58.33\%). About two thirds (8) of spondylolisthesis occurred at L4- L5 level and one third of patients, (4) at L5-S1 level. Regarding motor weakness, $5^{\text {th }}$ lumbar nerve root (L5) was involved in 5 patients $(41.62 \%)$ and $1^{\text {st }}$ sacral nerve root (S1) was involved in 3 patients $(25 \%)$. Intact motor function was found in 4 patients $(33.33 \%)$. In 6 patients $(50 \%)$ sensory impairment was found at the distribution of L5 and 3 patients (25\%) at the distribution of S1. Intact sensory function was found in 3 patients (25\%). Post operative hospital stay was between 2-3 weeks. The potential post operative complications were dural tear in 1 patient $(8.33 \%)$, foot drop in 1 patient $(8.33 \%)$. Maximum patients were in grade II spondylolisthesis. Others are shown in table I. Preoperative and postoperative scores of all the patients according to Modified Oswestry Low Back Pain Disability Questionnaire is shown in table II. Outcome of patients is presented in table III and final outcome is shown in table IV.

Table I. Distribution of patients according to grading $(\mathrm{n}=12)$ (Meyerding criteria)

\begin{tabular}{lcc}
\hline Grades & Number & Percentage \\
\hline Grade 1 & 3 & 25 \\
Grade 2 & 8 & 66.67 \\
Grade 3 & 1 & 8.33 \\
Grade 4 & 0 & 0 \\
\hline
\end{tabular}


Table II. Comparison of preoperative and postoperative scoring based on Modified oswestry low back pain disability questionnaire 4

\begin{tabular}{lccc}
\hline Code No & $\begin{array}{c}\text { Preoperative } \\
\text { score }\end{array}$ & $\begin{array}{c}\text { Postoperative } \\
\text { score }\end{array}$ & Result \\
\hline 1 & 28 & 18 & Better \\
2 & 25 & 16 & Better \\
3 & 26 & 07 & Excellent \\
4 & 27 & 15 & Better \\
5 & 25 & 31 & Worse \\
6 & 27 & 17 & Better \\
7 & 26 & 08 & Excellent \\
8 & 25 & 14 & Better \\
9 & 25 & 08 & Excellent \\
10 & 27 & 16 & Better \\
11 & 26 & 17 & Better \\
12 & 28 & 18 & Better \\
\hline
\end{tabular}
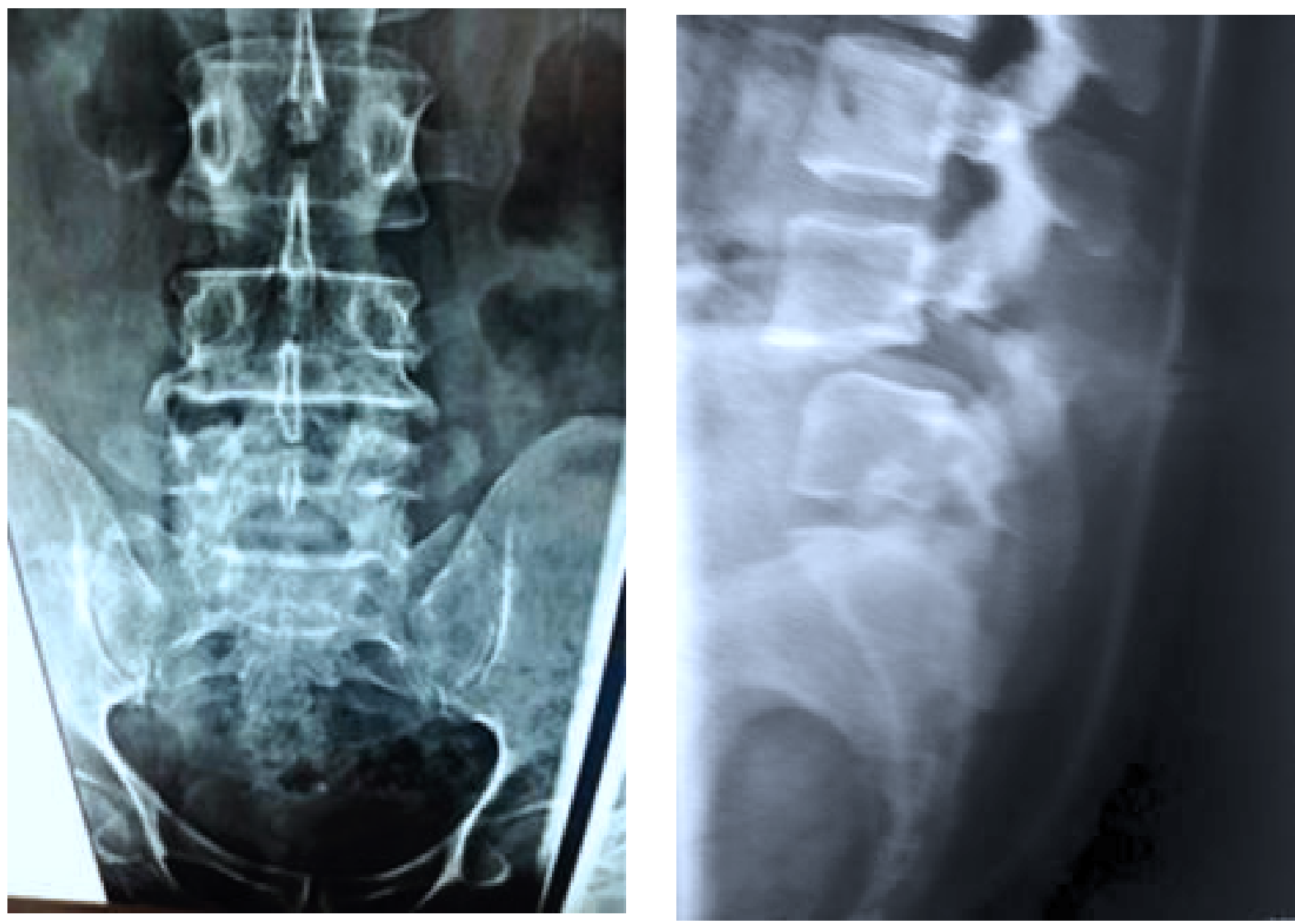

Figure 1. Preoperative X-ray A-P and lateral view of lumbosacral spines showing spondylolisthesis of L4 over L5. (Based on Modified oswestry low back pain disability questionnaire)

\begin{tabular}{lcc}
\hline Result & Number & Percentage \\
\hline Excellent & 3 & 25 \\
Better & 8 & 66.67 \\
Unchanged & 0 & 0 \\
Worse & 1 & 8.33 \\
\hline
\end{tabular}

Table IV. Final outcome of the study $(n=12)$

\begin{tabular}{lcc}
\hline Result & Number & Percentage \\
\hline Satisfactory & 11 & 91.67 \\
Unsatisfactory & 1 & 8.33 \\
\hline
\end{tabular}

Table III. Functional outcome of the study $(n=12)$ 

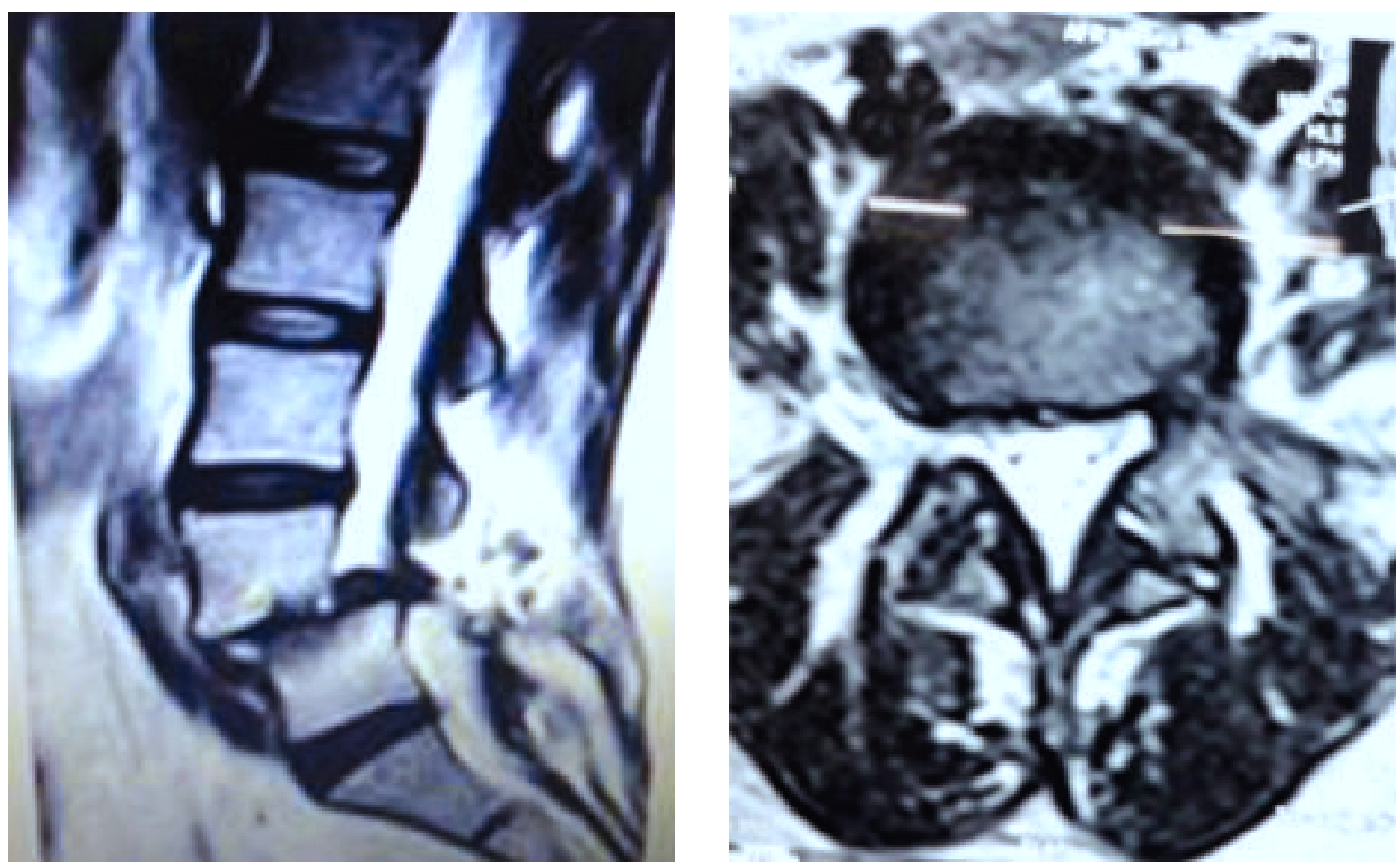

Figure 2. Preoperative MRI of lumbo sacral spines (sagital and axial view) showing spondylolisthesis of L4 over L5 and compression of nerve root.
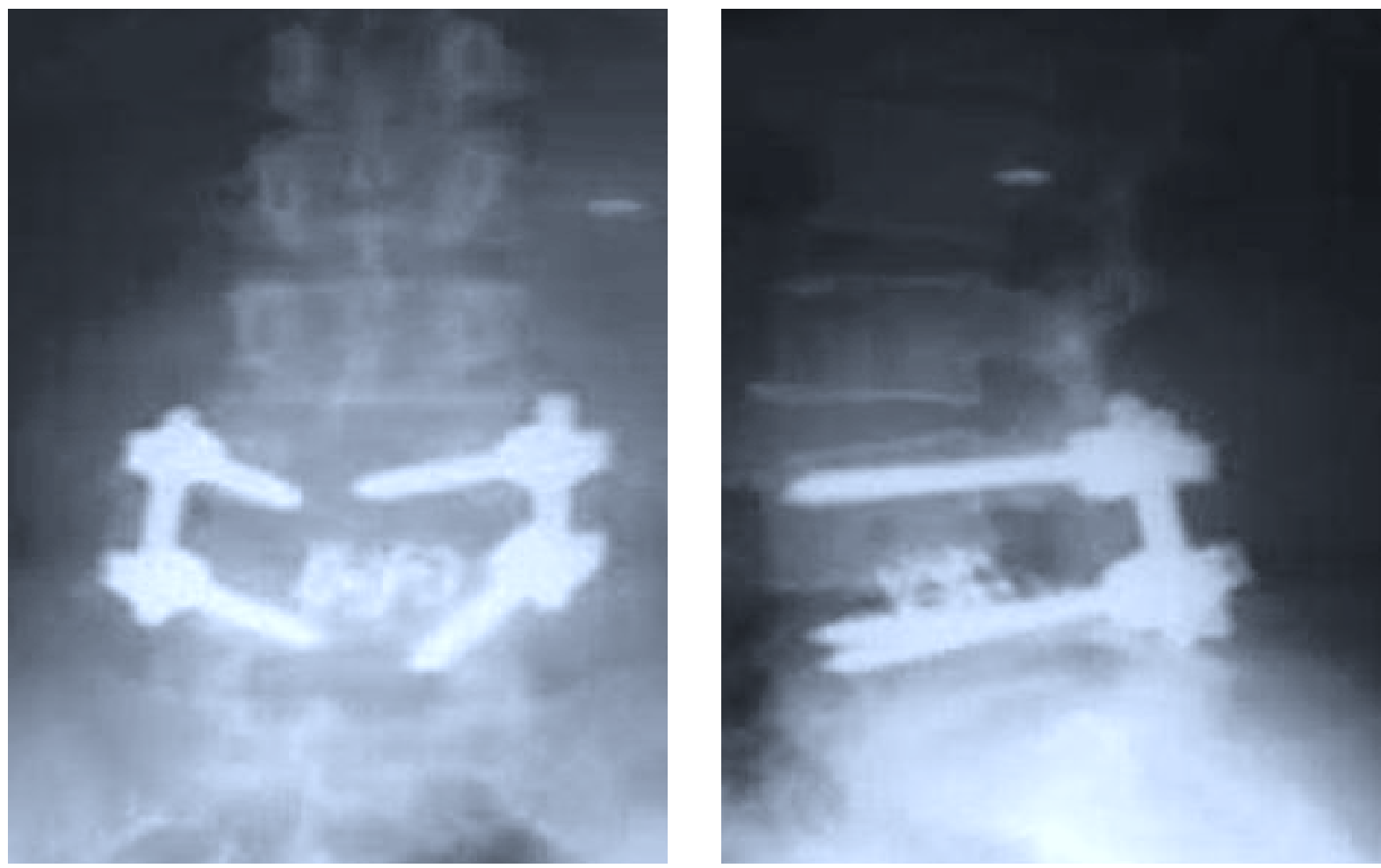

Figure 3. After decompression, stabilization and fusion.(one week after operation). 


\section{Discussion}

Spondylolisthesis can occur at any age. The purpose of treating symptomatic spondylolisthesis is to achieve early neurological decompression and stabilization for early rehabilitation. The pedicle is a power nucleus of a vertebra and allows a secure grip of all three columns. So, stabilization by transpedicular screws and rods offers three column stability. Pedicle screw fixation revolutionized spine surgery.

In this study, age of the patients varied from 21-70 years.Majority of patients belonged to age group 51-60 years, mean age was 437 years. This is close to the study of Inamdar et al. ${ }^{3}$, in which mean age was 41.4 years. High incidence ofspondylolisthesis in this age group is due to degenerative changes of spine.

Regarding the sex distribution of this study, males were 5 $(41.67 \%)$ and females were $7(58.33 \%)$ which was similar to the study of Zoher Ghogowala et $\mathrm{al}^{4}$, in which femals were two thirds (about 68\%). This may be due to women who suffer from early osteoporosis and negligence about diet and also poverty in our country.

In this series all patients were operated under general anaesthesia and by posterior midline incision and average operation time was 3.5 hours, which was close to the study of Inamdar et $\mathrm{al}^{3}$. They operated 10 patients by decompression and stabilization, average time needed for operation was 4 hours and done under general anaesthesia and posterior midline incision.

About postoperative complications, dural tear occurred in 1 patient $(8.33 \%)$. Dural tear was repaired with $5 / 0$ vicryl and there was no CSF leakage. One patient $(8.33 \%)$ developed foot drop that was treated surgically later on. In Kuslich et $\mathrm{al}^{5}$, series complications occurred in 4 to $10 \%$ of patients who underwent this procedure.

In this study all the patients underwent interbody fusion after decompression. Bone grafting augmented with cage was used in 5 cases $(41.67 \%)$. In this series bone grafts were harvested locally from spinous process and resected laminae. Many surgeons i.e Revit DJ et. $\mathrm{al}^{6}$, operated 32 patients and harvested autologous bone grafts from the posterior iliac crest. So, our study finding was not similar to his study.
In this study overall a satisfactory result was found in 11 patients $(91.67 \%)$ and unsatisfactory in 1 patient $(8.33 \%)$ over a follow up period of 6 months to 1 year. In Oscar \& Alfredo ${ }^{8}$ series, selective instrumentation was done in 32 patients.After a mean period of 3.4 years, they found satisfactory results in 27 patients $(84.4 \%)$. So, our operative success was near to them.

\section{Conclusion}

Based on the results shown above, it is concluded that results of surgical treatment of spondylolisthesis by decompression, stabilization with transpedicular screws and rods and and PLIF is an effective, safe and acceptable method. Though surgical procedures can not confirm lifelong recovery of the patients with symptoms, but do ensure a better and comfortable life style with protential improvement of leg symptons in case of spondylolisthesis.

Conflict of interest: Nothing to declare.

\section{References}

1. Eisenstein S, Tuli S, Govender S.The back. In: Solomon L, Warwick D, Nayagam S editors. Apleys System of Orthopaedics and Fractures. $9^{\text {th }}$ edition. Liverpool Uk. Hodder Arnold 1982: P484-86.

2. Curlee PM. Other Disorder of the spine. In: Canale ST, Beaty $\mathrm{JH}$, editors.Campbells operative orthopaedics. Eleventh edition. 2008; vol-II: P2290-91.

3. Inamdar DN, Alagappan M, ShyamL, Devadoss S, Devadoss A. Posterior lumbar interbody fusion versus intertransverse fusion in the treatment of lumbar spondylolisthesis. Journal of Orthopaedic Surgery 2006; 14(1):21-26.

4. Ghogawala Z, Edward MD, Benzel C. Prospective outcomes evaluation after decompression with or without instrumented fusion for lumbar stenosis and degenerative Grade 1 spondylolisthesis, J Neurosurg (Spine 1) 2004; 3: 267-72.

5. Kuslich, SD, UIstrom CL, Griffith SL, Ahem JW, Dowdle JD. The Bagby and Kuslich method of lumbar interbody fusion. History, techniques and 2-year follow-up results of a United States prospectives, multicenter trial. Spine 1998; 23(11): 1267-78

6. Rivet DJ, Jeck D, Brennan J , Epstein A, Laui C. Clinical outcome and complications with pedicle screw fixation augmented lumbar interbody fusion. J Neuro Serg (Spine), 2004; 1: 261-66.

7. Oscar M, Alfredo P. Selective instrumentation reduction and repair in low grade isthmic spondylolisthesis. Int Orthop 2004; 28: 180-82.

8. Meyerding, HW. Spondylolisthesis. Surg, Gynce and Obstet, 1932; $54:$ 371-77. 